Article

\title{
On the Bias in the Danckwerts' Plot Method for the Determination of the Gas-Liquid Mass-Transfer Coefficient and Interfacial Area
}

\author{
German E. Cortes Garcia ${ }^{1}$, Kevin M. P. van Eeten ${ }^{1}$, Michiel M. de Beer ${ }^{2}{ }^{\mathbb{D}}$, Jaap C. Schouten ${ }^{1}$ \\ and John van der Schaaf ${ }^{1, *}$ \\ 1 Laboratory of Chemical Reactor Engineering, Department of Chemical Engineering \& Chemistry, \\ Eindhoven University of Technology, P.O. Box 513, 5600 MB Eindhoven, The Netherlands; \\ g.e.cortes.garcia@tue.nl (G.E.C.G.); k.m.p.v.eeten@tue.nl (K.M.P.v.E.); j.c.scouten@tue.nl (J.C.S.) \\ 2 AkzoNobel Chemicals B.V., RD\&I, Expert Capability Group-Process Technology, Zutphenseweg 10, \\ 7418 AJ Deventer, The Netherlands; michiel.debeer@akzonobel.com \\ * Correspondence: j.vanderschaaf@tue.nl; Tel.: +31-40-247-2850; Fax: +31-40-244-6653
}

Received: 14 December 2017; Accepted: 11 February 2018; Published: 20 February 2018

\begin{abstract}
The Danckwerts' plot method is a commonly used graphical technique to independently determine the interfacial area and mass-transfer coefficient in gas-liquid contactors. The method was derived in 1963 when computational capabilities were limited and intensified process equipment did not exist. A numerical analysis of the underlying assumptions of the method in this paper has shown a bias in the technique, especially for situations where mass-transfer rates are intensified, or where there is limited liquid holdup in the bulk compared to the film layers. In fact, systematic errors of up to $50 \%$ in the interfacial area, and as high as $90 \%$ in the mass-transfer coefficients, can be expected for modern, intensified gas-liquid contactors, even within the commonly accepted validity limits of a pseudo-first-order reaction and Hatta numbers in the range of $0.3<\mathrm{Ha}<3$. Given the current computational capabilities and the intensified mass-transfer rates in modern gas-liquid contactors, it is therefore imperative that the equations for reaction and diffusion in the liquid films are numerically solved and subsequently used to fit the interfacial area and mass-transfer coefficient to experimental data, which would traditionally be used in the graphical Danckwerts' method.
\end{abstract}

Keywords: gas-liquid mass transfer; Danckwerts' plot method; numerical simulation; mass-transfer coefficient; interfacial area

\section{Introduction}

Novel types of process equipment have recently been developed in which the mixing and hydrodynamics of gasses and liquids directly lead to better gas-liquid mass-transfer performance [1-5]. By reducing limitations in heat and mass transfer, chemical processes can be performed at their intrinsic kinetic conditions. These intensified processes will help meet the societal demand for safer, more efficient, and economical production of chemicals.

Accurate measurements of the interfacial area for gas-liquid mass transfer $\left(a_{G L}\right)$, and of the gasand liquid-phase mass-transfer coefficients $\left(k_{G}\right.$ and $k_{L}$, respectively), are thus required in order to understand the effect of different design and operating parameters on the mass-transfer performance of gas-liquid contactors and reactors.

Numerous methods have been used to measure these parameters and several reviews about them are available in the literature [6-10]. The most commonly used methods rely on chemical and physical absorption experiments and, in most cases, they allow for the measurement of the volumetric mass-transfer coefficients (i.e., the products $k_{G} \cdot a_{G L}$ and $k_{L} \cdot a_{G L}$ ). However, it is often desired to measure $a_{G L}$ independently, since design and operating conditions affect each of these parameters differently. 
One of the methods most often used for the independent determination of $k_{L}$ and $a_{G L}$ is the Danckwerts' plot method. This method was proposed by Danckwerts et al. in 1963 [11] and it has been used ever since to characterize the mass-transfer performance of several gas-liquid contactors and reactors, such as stirred gas-liquid reactors [12], three-phase fluidized beds [13], packed columns [6], bubble columns [14], Venturi contactors [15], and even for gas-liquid-liquid systems [16]. The method relies on the absorption of gaseous A into a liquid, in which B is pre-dissolved. A and B react inside the liquid, increasing the concentration gradient of A near the interface, effectively enhancing the mass-transfer rate. The absorption rate can then be expressed as:

$$
R a_{G L}=k_{L} a_{G L} C_{A}^{*} E
$$

where $E$ represents the enhancement factor, which is defined as the factor with which the transport of A through the interface is increased due to the effect of reaction.

According to Hatta's theory [17], the enhancement factor for an irreversible first-order reaction can be expressed in terms of $\mathrm{Ha}$ as:

$$
E=\frac{1}{C_{A}^{*}}\left(C_{A}^{*}-\frac{C_{A}^{\infty}}{\cosh (H a)}\right) \frac{H a}{\tanh (H a)}
$$

where $H a$ is the Hatta number, defined by:

$$
H a=\frac{\sqrt{k_{2} D_{A} C_{B}^{\infty}}}{k_{L}}
$$

Based on surface renewal theory, Danckwerts further derived an approximation for the enhancement factor for the case where the bulk concentration of dissolved gas $\left(A^{\infty}\right)$ is zero [6]:

$$
E=\sqrt{1+H a^{2}}
$$

which holds for $\mathrm{Ha}>0.3$.

If the reaction is fast enough, i.e., $H a>3$, Equation (4) can be approximated as

$$
E=H a
$$

and the rate of absorption becomes independent of the mass-transfer coefficient

$$
R a_{G L}=a_{G L} C_{A}^{*} \sqrt{k_{2} D_{A} C_{B}^{\infty}}
$$

Equations (4) and (5) can also be applied to irreversible second-order reactions as long as the reactions can be considered pseudo-first-order. It should then hold that:

$$
H a<<k_{L}^{2} \cdot E_{i}
$$

Combining Equations (1) and (4) yields the following relationship for the absorption rate:

$$
R a_{G L}=a_{G L} C_{A}^{*} \sqrt{D_{A} k_{2} C_{B}^{\infty}+k_{L}^{2}}
$$

which can be rearranged to give:

$$
\left(\frac{R a_{G L}}{C_{A}^{*}}\right)^{2}=a_{G L}^{2} \cdot D_{A} \cdot k_{a p p}+\left(k_{L} a_{G L}\right)^{2}
$$


in which the apparent first-order rate constant is

$$
k_{a p p}=k_{2} C_{B}^{\infty}
$$

Chemical absorption experiments with a pseudo-first-order reaction can then be used to characterize the mass-transfer performance of gas-liquid contactors and reactors in two different ways: (a) by measuring $a_{G L}$ in the fast reaction regime (i.e., $3<H a<0.5 E_{i}$ ) based on Equation (6), and (b) by measuring both $a_{G L}$ and $k_{L}$ in the intermediate reaction regime (i.e., $0.3<H a<3$ ) based on Equation (9). Method (b) is known as the Danckwerts' plot method. This method uses a pseudo-first-order reaction between a liquid and an absorbed gas to measure the absorption rate at different apparent rate constants $\left(k_{a p p}\right)$. The data thus obtained is used to construct a Danckwerts' plot, as schematically depicted in Figure 1, from which $a_{G L}$ and $k_{L}$ can be found from the slope and the intercept, respectively. The apparent first-order rate constant can be varied by either changing the concentration of reactant $B$ or by modifying the reaction rate constant with the help of a catalyst [6].

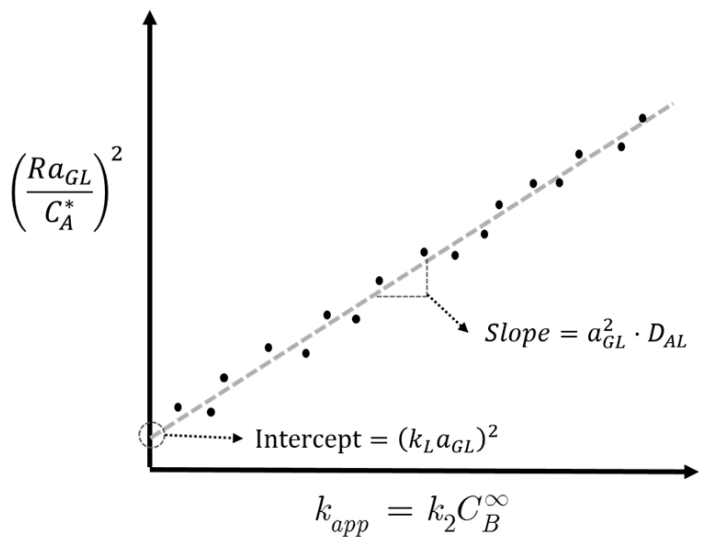

Figure 1. Schematic representation of the Danckwerts' plot method.

The method was developed in 1963 when there was no global trend in process intensification for the development of novel gas-liquid contactors. Although the method still has its merit, it has an important limitation: the existence of a systematic error, or bias, in the estimation of the mass-transfer coefficient $\left(k_{L}\right)$. This paper discusses this bias and its dependence on the Hatta number and on the relative liquid volume in the bulk versus that in the film layers and how this limits its use for novel, intensified gas-liquid contactors.

\section{Numerical Methods}

Every experimental method is only as accurate as the underlying data. In order to present the bias in the Danckwerts' plot method in the most accurate way, data is generated by solving the continuum equations for diffusion and reaction in the liquid-film layer near the interface. Since this simplified, one-dimensional (1D)-diffusion model is the basis for the original method, the same system is solved here, but in a more rigorous way. The numerical data generated with the following method will then be subjected to the Danckwerts' plot. The mass-transfer parameters will be extracted from the slope and the intercept and will be compared to parameters initially fixed in the model in order to analyze the accuracy of the method.

\subsection{Diffusion-Reaction Model}

The numerical method is based on a Two-Film model [18]. In this model, reactant A is in the gas phase and reactant $B$ is in the liquid as shown in Figure 2. When gas-side mass transfer is neglected, the concentration of $\mathrm{A}$ on the interface is determined by the partial pressure of $\mathrm{A}$ in the gas and by 
Henry's solubility constant $(\mathrm{H})$. Component A diffuses through the film of thickness $\delta$ into the bulk while simultaneously reacting with $B$, which diffuses in the opposite direction.

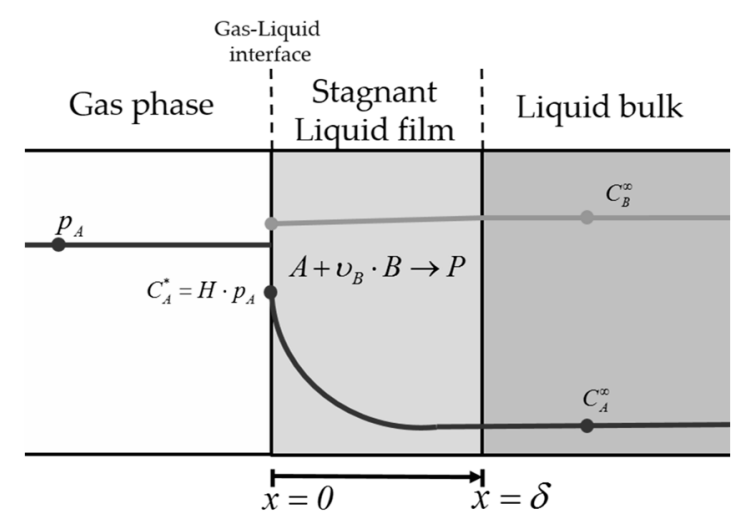

Figure 2. Concentration profiles of A and B within stagnant liquid film (Film Theory).

The liquid-side mass-transfer coefficient is determined by the thickness of this stagnant liquid film and the diffusivity of the species $\left(D_{A}\right)$, as shown in Equation (11).

$$
k_{L}=\frac{D_{A}}{\delta}
$$

A mass balance over the liquid film results in the following two equations:

$$
\begin{gathered}
D_{A} \frac{d^{2} C_{A}}{d x^{2}}=k_{2} C_{A} C_{B} \\
D_{B} \frac{d^{2} C_{B}}{d x^{2}}=v_{B} \cdot k_{2} C_{A} C_{B}
\end{gathered}
$$

These two equations can be solved simultaneously in MATLAB (R2017a, MathWorks, Inc., Natick, MA, USA) using the bvp4c solver subject to boundary conditions (14)-(17) to obtain the concentration profiles of $A$ and $B$ within the liquid film.

$$
\begin{gathered}
\left.C_{A}\right|_{x=0}=C_{A}^{*} \\
\left.\left(-D_{A} \frac{d C_{A}}{d x}\right)\right|_{x=\delta} \cdot a_{G L}=k_{2} C_{A}^{\infty} C_{B}^{\infty} \cdot\left(\varepsilon_{l}-\delta \cdot a_{G L}\right) \\
\left.\frac{d C_{B}}{d x}\right|_{x=0}=0 \\
\left.C_{B}\right|_{x=\delta}=C_{B}^{\infty}
\end{gathered}
$$

Boundary condition (15) states that at $x=\delta$ the total flux of A equals the rate of reaction in the liquid bulk. Consequently, $\left(\varepsilon_{l}-\delta \cdot a_{G L}\right)$ equals the bulk volume, excluding the liquid film.

After solving Equations (12) and (13), the overall rate of absorption can be calculated from the slope of the concentration profile at the gas-liquid interface, given by Equation (18).

$$
R a_{G L}=-D_{A} \cdot\left(\frac{d C_{A}}{d x}\right)_{x=0} \cdot a_{G L}
$$

This model was used to simulate a bubble column, a packed bed, and a rotating packed bed so that the effect of the holdup $\varepsilon_{l}$ and of the magnitude of the interfacial area $a_{G L}$ can be accounted for. The model requires input for the liquid holdup and interfacial area. Typical values occurring in bubble 
columns, packed beds, and rotating packed beds are chosen as represented in Table 1. Please note that $k_{L}$ is fixed in this model by choosing a value for $\delta$ in boundary conditions (15) and (17), while $a_{G L}$ is set via Equation (18). Other parameters used in the simulation are shown in Table 2.

Table 1. Parameters used in the simulations.

\begin{tabular}{|c|c|c|c|c|c|}
\hline Equipment & $\varepsilon_{l}\left(\mathrm{~m}_{\mathrm{L}}{ }^{3} \cdot \mathrm{m}_{\mathrm{R}}{ }^{-3}\right)$ & $a_{G L}\left(\mathrm{~m}_{i}^{2} \cdot \mathrm{m}_{\mathrm{L}}^{-3}\right)$ & $k_{L}\left(\mathrm{~m}_{\mathrm{L}}^{3} \cdot \mathrm{m}_{i}^{-2} \cdot \mathrm{s}^{-1}\right)$ & $\left(\varepsilon_{l} / a_{G L} \cdot \delta\right)$ & References \\
\hline Bubble Column & 0.90 & 50 & $\begin{array}{l}1.0 \times 10^{-3} \\
1.0 \times 10^{-4}\end{array}$ & $\begin{array}{l}1.0 \times 10^{4} \\
1.0 \times 10^{3}\end{array}$ & [19-21] \\
\hline Packed Bed & 0.15 & 150 & $\begin{array}{l}1.0 \times 10^{-3} \\
1.0 \times 10^{-4}\end{array}$ & $\begin{array}{l}5.6 \times 10^{2} \\
5.6 \times 10^{1}\end{array}$ & [22-24] \\
\hline $\begin{array}{c}\text { Rotating } \\
\text { Packed Bed }\end{array}$ & 0.03 & 700 & $\begin{array}{l}1.0 \times 10^{-3} \\
1.0 \times 10^{-4}\end{array}$ & $\begin{array}{c}2.4 \times 10^{1} \\
2.4 \times 10\end{array}$ & [25-27] \\
\hline
\end{tabular}

Table 2. Other parameters used in the simulations (based on properties of the system $\mathrm{CO}_{2} / \mathrm{NaOH}$ [6]).

\begin{tabular}{cc}
\hline Parameter & Value \\
\hline$D_{A}\left(\mathrm{~m}_{\mathrm{L}}^{4} \cdot \mathrm{m}_{i}^{-2} \cdot \mathrm{s}^{-1}\right)$ & $1.80 \times 10^{-9}$ \\
$D_{B}\left(\mathrm{~m}_{\mathrm{L}}^{4} \cdot \mathrm{m}_{i}{ }^{-2} \cdot \mathrm{s}^{-1}\right)$ & $3.10 \times 10^{-9}$ \\
$C_{B}{ }^{\infty}\left(\mathrm{mol} \cdot \mathrm{m}_{\mathrm{L}}{ }^{-3}\right)$ & $1.00 \times 10^{3}$ \\
$C_{A}^{*}\left(\mathrm{~mol} \cdot \mathrm{m}_{\mathrm{L}}{ }^{-3}\right)$ & $3.90 \times 10^{-1}$ \\
$E_{i}$ & $2.18 \times 10^{2}$ \\
\hline
\end{tabular}

From the results following Equation (18), a Danckwerts' plot can be finally made from which the regressed values of $a_{G L}$ and $k_{L}$ are compared with their counterparts in Table 1 .

\section{Results and Discussion}

\subsection{Accuracy of the Danckwerts' Plot Method}

The model described in Section 2.1 was used to obtain the concentration profiles for a bubble column using its respective values from Tables 1 and 2 , with a $k_{L}$ value of $1.0 \times 10^{4} \mathrm{~m}_{\mathrm{L}}^{3} \cdot \mathrm{m}_{i}{ }^{-2} \cdot \mathrm{s}^{-1}$. Figure 3a shows typical concentration profiles for a bubble column at Hatta numbers between 0.3 and 3, with a spacing between them of $\Delta H a=0.15$. The concentration of $\mathrm{B}$ is nearly constant and the reaction can therefore be considered pseudo-first-order in A. Since Equation (4) holds, the graphical method should, in principle, be able to be applied to obtain $a_{G L}$ and $k_{L}$.
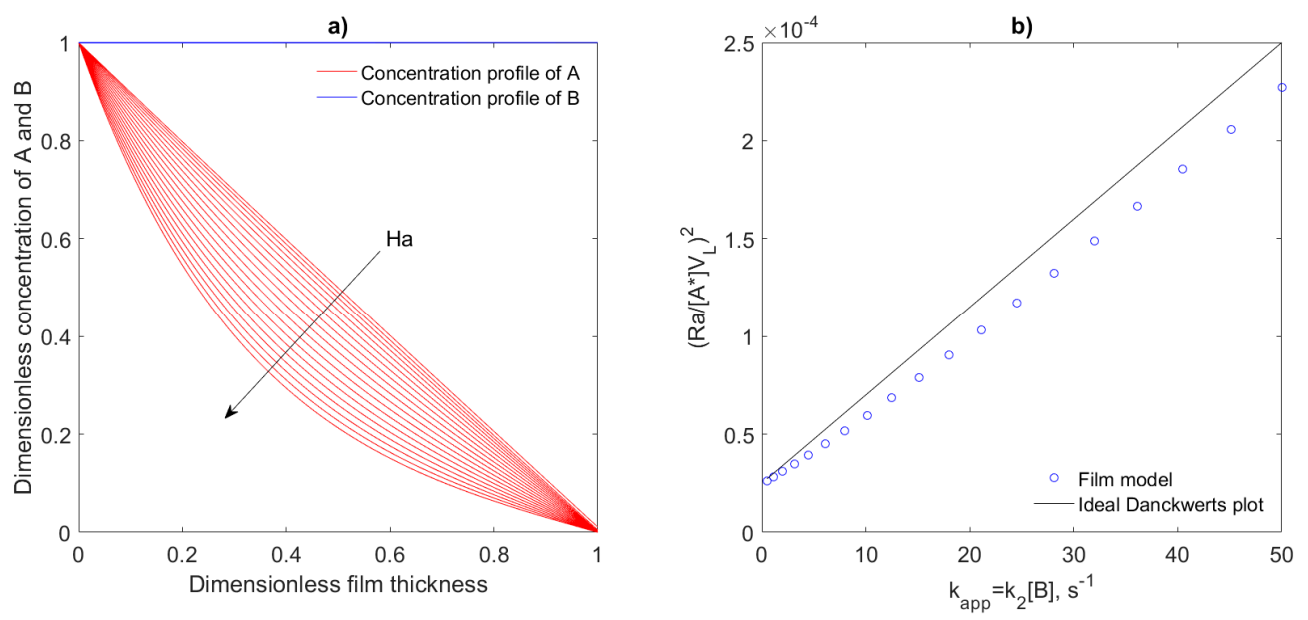

Figure 3. Concentration profiles (a) and Danckwerts' plot (b) for $\varepsilon_{l} /\left(a_{G L} \cdot \delta\right)=1.0 \times 10^{3}$ (bubble column). 
In Figure $3 b$, the results from the simulation data are plotted alongside the theoretical line expected from the Danckwerts' method using $a_{G L}$ and $k_{L}$ as reported in Table 1 for a bubble column. If the method were accurate enough, regressing the simulation results would produce a straight line with a very similar slope and intercept to those of the "ideal" plot. Nevertheless, inspection of this figure shows that the slope of the numerical data approaches that of the theoretical line only for high values of the apparent rate constant. On the other hand, the Danckwerts' method results in the right value of the mass-transfer coefficient at low values of $k_{a p p}$ at the cost of accuracy in $a_{G L}$. In addition to this effect, a small deviation in the slope of $k_{a p p}$ further reduced the accuracy in the mass-transfer coefficient. It is thus clear that a trade-off exists between the accuracy at which each of these parameters can be estimated.

Since the slope and the intercept of a regressed plot change as $k_{a p p}$ increases, the mass-transfer parameters thus calculated should vary with the Hatta number. As the Hatta number depends on the mass-transfer coefficient, it cannot be known a priori at which position in Figure $3 \mathrm{~b}$ the experiments were performed, and thus to which accuracy $a_{G L}$ and $k_{L}$ were determined.

To study the effect of Hatta number on the accuracy of the method, regressions of the simulation data were performed over a wide range of Hatta numbers. For each Hatta number, a regression was made over five equidistant points in the range $H a<x<H a+0.1$. From this, $a_{G L}, k_{L}$ and their corresponding percentage errors with respect to the values in Table 1 were calculated. The results for a bubble column are shown in Figure 4. The shaded area corresponds to the intermediate reaction regime, i.e., $0.3<\mathrm{Ha}<3$, where the Danckwerts' plot method should hold. In this range of $\mathrm{Ha}$, the interfacial area is underestimated by up to $20 \%$, it then becomes more accurate for faster reactions, i.e., $\mathrm{Ha}>3$, and starts to deviate again for $\mathrm{Ha}>100$, or $\mathrm{Ha} \sim 0.5 \mathrm{Ei}$. At this point, the reaction is too fast for the assumption of pseudo-first-order to be valid. The source of error in the intermediate reaction regime comes from the misprediction of the Enhancement factor by Equation (4), which was derived under the assumption that the concentration of reactant $A$ in the liquid bulk equals zero, an assumption that holds well for fast reactions but not so well for intermediate and slow reactions relative to the mass-transfer rate. These results show that chemical absorption can lead to very accurate measurements of the interfacial area if a fast reaction is used while a loss of accuracy should be expected when using intermediate reactions. The mass-transfer coefficient, on the other hand, lies close-without fully converging - to the predetermined value of $1.0 \times 10^{-4} \mathrm{~m}_{\mathrm{L}}^{3} \cdot \mathrm{m}_{i}^{-2} \cdot \mathrm{s}^{-1}$ when it is measured within the intermediate reaction regime but is highly mispredicted in the fast reaction regime. In this sense, it does not seem possible to determine, simultaneously, both mass-transfer parameters in an accurate way.

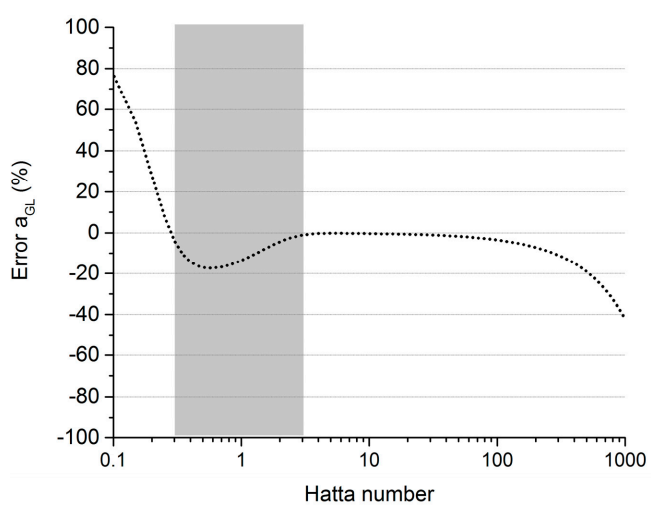

(a)

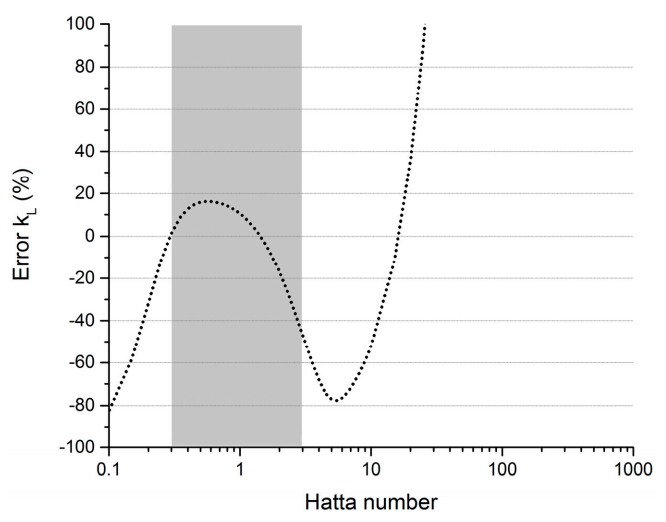

(b)

Figure 4. Percentage error in the estimation of (a) interfacial area $\left(a_{\mathrm{GL}}\right)$ and $(\mathbf{b})$ mass-transfer coefficient $\left(k_{L}\right)$ using the Danckwerts' plot over a wide range of $H a$ for a Bubble column, $\varepsilon_{l} /\left(a_{G L} \cdot \delta\right)=1000$. 


\subsection{Bias in the Determination of $k_{L}$ and Effect of the Ratio $\varepsilon_{l} /\left(a_{G L} \cdot \delta\right)$}

Figure 5 shows similar plots to those in Figure 4 but for the intermediate reaction regime only. The different lines represent one of the three equipment types previously mentioned, with their characteristic hydrodynamic and mass-transfer parameters listed in Table 1. It can be seen in the figure that again there is always a bias in the determination of $a_{G L}$ and $k_{L}$ At higher Hatta numbers, $a_{G L}$ can be determined more accurately, while the error in $k_{L}$ is less, but never fully disappears, at lower Hatta numbers. Moreover, the error at lower Hatta numbers rapidly increases when $\varepsilon_{l} /\left(a_{G L} \cdot \delta\right)$ decreases.

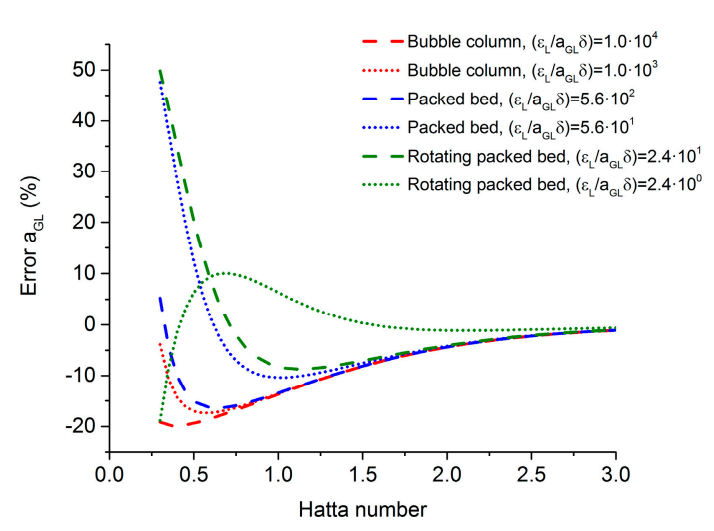

(a)

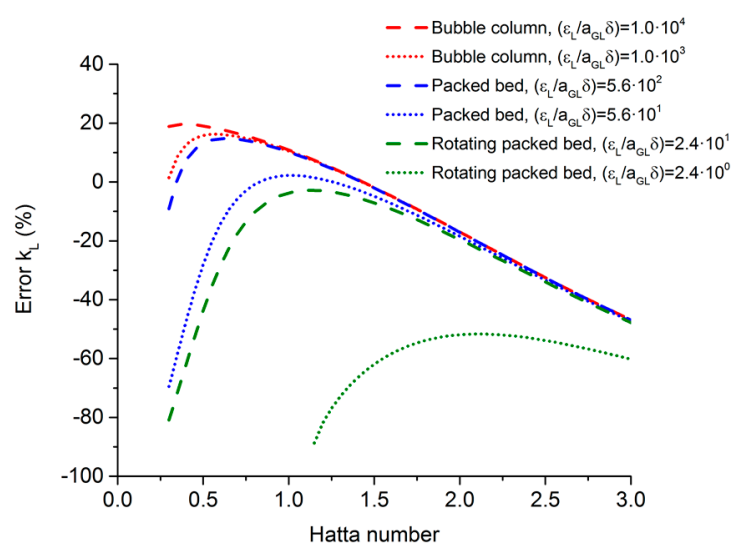

(b)

Figure 5. Percentage error in estimation of (a) interfacial area $\left(a_{G L}\right)$ and (b) mass-transfer coefficient $\left(k_{L}\right)$ using the Danckwerts' plot in the intermediate reaction regime for the different equipment.

These results show that the Danckwerts' plot method leads to acceptable estimations of the interfacial area but estimates of the mass-transfer coefficient are subject to a systematic error. This error becomes more significant as the ratio of liquid in the bulk over liquid in the film layers decreases, i.e., as $\varepsilon_{l} /\left(a_{G L} \cdot \delta\right)$ decreases. The method has been said to be valid for $0.3<H a<3$; however, the exact range depends on the validity of the assumption that $A^{\infty}$ is close to zero. This assumption can only hold when the rate of reaction in the bulk is large enough to prevent the presence of unreacted $\mathrm{A}$ in the bulk itself. The lower limit of this range is located at $H a=0.3$ for systems with large volumes of bulk, such as bubble columns. However, this lower limit shifts towards higher Ha numbers as $\varepsilon_{l} /\left(a_{G L} \cdot \delta\right)$ decreases. If this ratio becomes too small, which may occur with process-intensified equipment, at some point an accurate determination of $k_{L}$ cannot be obtained any longer. This is true even without considering the possible accumulation in time of unreacted A for systems with limited bulk, a phenomenon previously described by Elk et al. [28]. A natural approach would then be to introduce a correction factor in terms of the ratio $\varepsilon_{l} /\left(a_{G L} \cdot \delta\right)$ to obtain a revised and more general expression for the range of validity of the method. In this way, it could be applied with more certainty to reactors with different relative amounts of liquid bulk. However, according to Equations (12) and (13) and boundary conditions (14)-(17), the range of validity depends not only on this ratio but also on the reaction rate constant, the stoichiometric coefficient, and the diffusivity of species $\mathrm{A}$ and $\mathrm{B}$ and their concentration at the interface and in the liquid bulk, respectively. Introducing such a revised range of validity for the method thus seems unfeasible and of little practical significance as it would require knowledge on the mass-transfer coefficient a priori.

Even inside the traditional limits of $0.3<\mathrm{Ha}<3, k_{L}$ is subject to a bias of up to $90 \%$ while the interfacial area is subject to a bias of up to $50 \%$. In this perspective, it is interesting to note the findings of Cents et al. [29], who measured $k_{L} \cdot a_{G L}$ simultaneously by physical desorption and by chemical absorption, ending up with differences of about $64 \%$ between both measurements.

In intensified equipment, where there is a limited amount of liquid in the bulk and the mass-transfer coefficient is large, the interval in allowable Hatta numbers becomes too small to 
make accurate predictions with the Danckwerts' method. The method can therefore only be used to estimate the interfacial area accurately when considerable care is taken that the assumptions of zero bulk concentration of solute gas and large bulk volumes are satisfied. In addition, the method only allows for an order of magnitude estimation of $k_{L}$. A more accurate way to obtain the mass-transfer parameters from experimental data would be to fit $k_{L}$ and $a_{G L}$ in a numerical simulation of the equations of reaction and diffusion.

\section{Conclusions}

The Danckwerts' plot method results from a mathematical approximation for the enhancement factor for intermediate reactions. The derivation of the Danckwerts' plot equation has a solid mathematical basis and therefore it has been used often for the simultaneous determination of the mass-transfer coefficient and the effective interfacial area of gas-liquid absorbers and reactors. However, this method was developed more than 50 years ago, when computational capability was limited and process-intensified equipment types were not under development. At this time, there was thus no need and no computational possibility to study the effect that the underlying assumptions had on the accuracy of the method. This work shows that the Danckwerts' method can only lead to fair estimates of the mass-transfer coefficient over a very limited range of Hatta numbers, depending on the relative liquid volume in the bulk versus that in the film layers. Nonetheless, the accuracy in $k_{L}$ comes at the cost of a loss in accuracy in the prediction of the interfacial area. On the other hand, if the method is applied to measure the interfacial area, it comes at a loss in accuracy in $k_{L}$. A systematic error appears then to exist in the method, since $k_{L}$ cannot be determined accurately even using simulated absorption data. A bias of up to $90 \%$ in the mass-transfer coefficient and of up to $50 \%$ in the interfacial area was found for the equipment simulated. A preferred approach to isolate $k_{L}$ from $a_{G L}$ would be to use the chemical absorption method (either with a Danckwerts' plot or with single measurements) to find the interfacial area and to use physical absorption experiments to measure $k_{L} \cdot a_{G L}$. Moreover, with the current computational power, a more accurate method would be to fit $k_{L}$ and $a_{G L}$ in a numerical simulation of the equations of reaction and diffusion to experimental data that would typically be subjected to the graphical Danckwerts' method.

Acknowledgments: This research was carried out within the HighSinc program-a joint development between AkzoNobel and the Department of Chemical Engineering and Chemistry from Eindhoven University of Technology - where $12 \mathrm{PhD}$ students will work on various aspects and applications of HiGee technologies.

Author Contributions: German E. Cortes Garcia: Conceived and designed the simulations, analyzed the data, and wrote the paper. Kevin M. P. van Eeten: Co-wrote the paper and helped interpret the results. Michiel M. de Beer: Co-wrote the paper and helped interpret the results. Jaap C. Schouten: Co-wrote the paper and helped interpret the results. John van der Schaaf: Initiated the research, co-wrote the paper, and helped interpret the results.

Conflicts of Interest: The authors declare no conflict of interest.

\section{Nomenclature}

$a_{G L} \quad$ Effective gas-liquid interfacial area, $\mathrm{m}_{i}{ }^{2} \cdot \mathrm{m}_{\mathrm{R}}{ }^{-3}$

$C_{A} \quad$ Concentration of solute gas A within stagnant liquid film, mol $\cdot \mathrm{m}_{\mathrm{L}}{ }^{-3}$

$C_{A}{ }^{*} \quad$ Concentration of solute gas $A$ at the gas-liquid interphase, $\mathrm{mol} \cdot \mathrm{m}_{\mathrm{L}}{ }^{-3}$

$C_{A}^{\infty} \quad$ Concentration of solute gas A in liquid bulk, $\mathrm{mol} \cdot \mathrm{m}_{\mathrm{L}}{ }^{-3}$

$C_{B} \quad$ Concentration of liquid reactant $B$ within stagnant liquid film, $\mathrm{mol} \cdot \mathrm{m}_{\mathrm{L}}{ }^{-3}$

$C_{B}{ }^{\infty} \quad$ Concentration of liquid reactant $B$ in liquid bulk, mol $\cdot \mathrm{m}_{\mathrm{L}}{ }^{-3}$

$D_{A} \quad$ Diffusion coefficient of component $\mathrm{A}$ in the liquid, $\mathrm{m}_{\mathrm{L}}^{4} \cdot \mathrm{m}_{i}{ }^{-2} \cdot \mathrm{s}^{-1}$

$D_{B} \quad$ Diffusion coefficient of component B in the liquid, $\mathrm{m}_{\mathrm{L}}^{4} \cdot \mathrm{m}_{i}{ }^{-2} \cdot \mathrm{s}^{-1}$

E Enhancement factor

$E_{i} \quad$ Enhancement factor for an instantaneous reaction, defined by $E_{i}=1+\frac{D_{B L}}{D_{A}} \cdot \frac{C_{B}^{\infty}}{v_{B} \cdot C_{A}^{*}}$ 


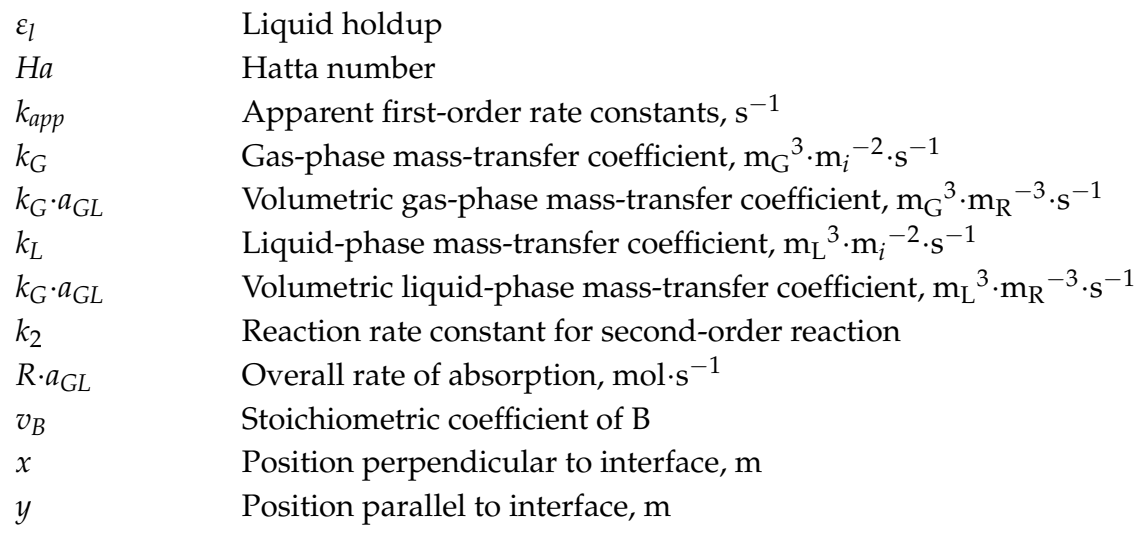

\section{References}

1. Van Eeten, K.M.P.; Verzicco, R.; Van Der Schaaf, J.; Van Heijst, G.J.F.; Schouten, J.C. A numerical study on gas-liquid mass transfer in the rotor-stator spinning disc reactor. Chem. Eng. Sci. 2015, 129, 14-24. [CrossRef]

2. De Beer, M.M.; Keurentjes, J.T.F.; Schouten, J.C.; Van Der Schaaf, J. Bubble formation in co-fed gas-liquid flows in a rotor-stator spinning disc reactor. Int. J. Multiph. Flow 2016, 83, 142-152. [CrossRef]

3. Haseidl, F.; Pottbäcker, J.; Hinrichsen, O. Gas-liquid mass transfer in a rotor-stator spinning disc reactor: Experimental study and correlation. Chem. Eng. Process. Process Intensif. 2016, 104, 181-189. [CrossRef]

4. Chen, Y.; Lin, C.; Liu, H. Mass transfer in a rotating packed bed with various radii of the bed. Ind. Eng. Chem. Res. 2005, 44, 7868-7875. [CrossRef]

5. Garcia, G.E.C.; Van Der Schaaf, J.; Kiss, A.A. A review on process intensification in higee distillation. J. Chem. Technol. Biotechnol. 2017, 92, 1136-1156. [CrossRef]

6. Danckwerts, P.V. Gas-Liquid Reactions; Mcgraw-Hill Book Co.: New York, NY, USA, 1970.

7. Rejl, J.F.; Linek, V.; Moucha, T.; Valenz, L. Methods standardization in the measurement of mass-transfer characteristics in packed absorption columns. Chem. Eng. Res. Des. 2009, 87, 695-704. [CrossRef]

8. Hegely, L.; Roesler, J.; Alix, P.; Solaize, D.; Rouzineau, D.; Meyer, M. Absorption methods for the determination of mass transfer parameters of packing internals: A literature review. AIChE J. 2017, 63. [CrossRef]

9. Last, W.; Stichlmair, J. Determination of mass transfer parameters by means of chemical absorption. Chem. Eng. Technol. 2002, 25, 385-391. [CrossRef]

10. Hoffmann, A.; Mackowiak, J.F.; Gorak, A.; Haas, M.; Loning, J.-M.; Runowski, T.; Hallenberger, K. Standardization of mass transfer measurements. a basis for the description of absorption processes. Chem. Eng. Res. Des. 2007, 85, 40-49. [CrossRef]

11. Danckwerts, P.V.; Kennedy, A.M.; Roberts, D. Kinetics of $\mathrm{CO}_{2}$ absorption in alkaline solutions-II. Absorption in packed column and tests of surface-renewal models. Chem. Eng. Sci. 1963, 18, 63-72. [CrossRef]

12. Linek, V.; Kordac, M.; Moucha, T. Mechanism of mass transfer from bubbles in dispersions part II: Mass transfer coefficients in stirred gas-liquid reactor and bubble column. Chem. Eng. Process. 2005, 44, 121-130. [CrossRef]

13. Strumillo, C.; Kundra, T. Interfacial area in three-phase fluidized beds. Chem. Eng. Sci. 1976, 32, $229-232$. [CrossRef]

14. Maalej, S.; Benadda, B.; Otterbein, M. Interfacial area and volumetric mass transfer coefficient in a bubble reactor at elevated pressures. Chem. Eng. Sci. 2003, 58, 2365-2376. [CrossRef]

15. Gourich, B.; Vial, C.; Soulami, M.B.; Zoulalian, A.; Ziyad, M. Comparison of hydrodynamic and mass transfer performances of an emulsion loop-venturi reactor in cocurrent downflow and upflow configurations. Chem. Eng. J. 2008, 140, 439-447. [CrossRef]

16. Cents, A.H.G.; Brilman, D.W.F.; Versteeg, G.F. Gas absorption in an agitated gas-liquid-liquid system. Chem. Eng. Sci. 2001, 56, 1075-1083. [CrossRef]

17. Hatta, S. Technological Reports of Tohoku University; Tohoku University: Sendai, Japan, 1932; Volume 10, p. 119.

18. Whitman, W.G. The two-film theory of gas absorption. Int. J. Heat Mass Transf. 1962, 5, 429-433. [CrossRef] 
19. Pohorecki, R.; Moniuk, W.; Zdrojkowski, A. Hydrodynamics of a bubble column under elevated pressure. Chem. Eng. Sci. 1999, 54, 5187-5193. [CrossRef]

20. Kulkarni, A.A.; Joshi, J.B.; Kumar, V.R.; Kulkarni, B.D. Simultaneous measurement of hold-up profiles and interfacial area using lda in bubble columns: predictions by multiresolution analysis and comparison with experiments. Chem. Eng. Sci. 2001, 56, 6437-6445. [CrossRef]

21. Bouaifi, M.; Hebrard, G.; Bastoul, D.; Roustan, M. A comparative study of gas hold-up, bubble size, interfacial area and mass transfer coefficients in stirred gas-liquid reactors and bubble columns. Chem. Eng. Process. 2001, 40, 97-111. [CrossRef]

22. Sahay, B.N.; Sharma, M.M. Effective interfacial area and liquid and gas side mass transfer coefficients in a packed column. Chem. Eng. Sci. 1973, 28, 41-47. [CrossRef]

23. Shulman, H.L.; Ulrich, C.F.; Wells, N. Performance of packed columns. AIChE J. 1955, 1, 247-253. [CrossRef]

24. Piché, S.; Grandjean, B.P.A.; Larachi, F. Reconciliation procedure for gas-liquid interfacial area and mass-transfer coefficient in randomly packed towers. Ind. Eng. Chem. Res. 2002, 41, 4911-4920. [CrossRef]

25. Zheng, X.; Chu, G.; Kong, D.; Luo, Y.; Zhang, J.; Zou, H. Mass transfer intensification in a rotating packed bed with surface-modified nickel foam packing. Chem. Eng. J. 2016, 285, 236-242. [CrossRef]

26. Luo, Y.; Chu, G.; Zou, H.; Zhao, Z.; Dudukovic, M.P.; Chen, J. Gas-liquid effective interfacial area in a rotating packed bed. Ind. Eng. Chem. Res. 2012. [CrossRef]

27. Burns, J.R.; Jamil, J.N.; Ramshaw, C. Process intensification: Operating characteristics of rotating packed beds-Determination of liquid hold-up for a high-voidage structured packing. Chem. Eng. Sci. 2000, 55, 2401-2415. [CrossRef]

28. Van Elk, E.P.; Knaap, M.C.; Versteeg, G.F. Application of the penetration theory for gas-liquid mass transfer without liquid bulk. differences with systems with a bulk. Chem. Eng. Res. Des. 2007, 85, 516-524. [CrossRef]

29. Cents, A.H.G.; De Bruijn, F.T.; Brilman, D.W.F.; Versteeg, G.F. Validation of The Danckwerts-plot technique by simultaneous chemical absorption of $\mathrm{CO}_{2}$ and physical desorption of $\mathrm{O}_{2}$. Chem. Eng. Sci. 2005, 60, 5809-5818. [CrossRef] 